
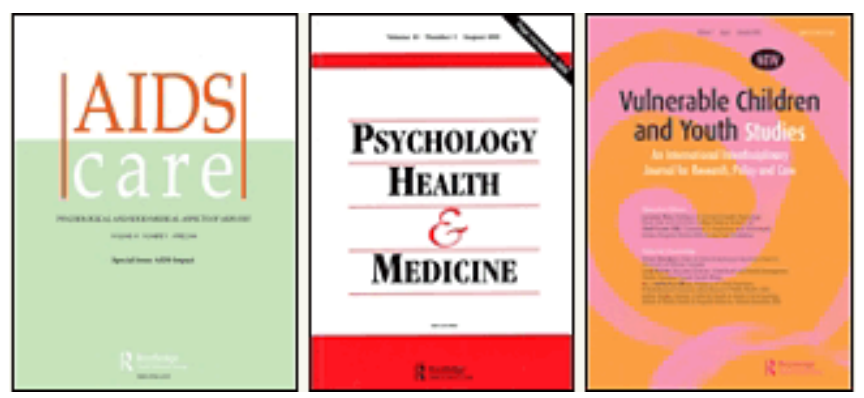

\title{
Orphanhood and vulnerability: a conduit to poor child health outcomes in Rwanda
}

\begin{tabular}{|r|l|}
\hline Journal: & $\begin{array}{l}\text { AIDS Care - Psychology, Health \& Medicine - Vulnerable Children } \\
\text { and Youth Studies }\end{array}$ \\
\hline Manuscript ID: & AC-2009-02-0085.R1 \\
\hline Journal Selection: & AIDS Care \\
\hline Keywords: & $\begin{array}{l}\text { Orphaned and Vulnerable Children, Child morbidity, Rwanda, } \\
\text { Graphical Chain Models, Demographic and Health Surveys }\end{array}$ \\
\hline
\end{tabular}

\section{(s) ScholarONE" \\ Manuscript Central}




\section{Orphanhood and vulnerability: a conduit to poor child health outcomes in Rwanda}

\section{Introduction}

This paper investigates the susceptibility of Orphaned and Vulnerable Children (OVC) towards fever and respiratory related illnesses and disentangles the complex associations that explain these health outcomes. Many children in Africa have become orphaned and vulnerable as a result of HIV/AIDS. By 2010, it is estimated that about 18 million children below age 18 would be classified as OVCs due to HIV/AIDS (UNICEF, 2005). In Rwanda, 220,000 children are estimated to have lost one or both parents because of HIV/AIDS (UNAIDS, 2008). The survival, growth and development of OVCs are greatly threatened as these children are subject to social neglect and discrimination (UNICEF, 2006).

The intra-household and environmental factors that affect the health status of OVCs are difficult to determine in Rwanda, which has not fully recovered from the impact of the 1994 genocide and periodic economic depression. The term "Orphaned and Vulnerable Children" has been used widely in the literature to describe children who have been orphaned or made vulnerable as a result of HIV/AIDS (Schenk et al., 2008; Skinner et al., 2006; Andrews et al., 2006; Stover et al., 2006; Bhargava \& Bigombe, 2003; Matshalaga \& Powell, 2002). However, there is no universal consensus to its definition (Skinner et al., 2006). We follow the definition used by the Rwandan Demographic and Health Surveys (RDHS) based on UN recommendations (UNICEF, 2005). OVCs are defined as those who (i) have lost one or both parents, (ii) one or both parents have been chronically ill for at least three months within the 12 months preceding the survey, (iii) live in a household where at least one adult (18-59 
years old) has been chronically ill for at least three months within the 12 months preceding the survey or (iv) live in a household where at least one adult (18-59 years old) has died in the past 12 months after being chronically ill for at least three months (Institut National de la Statistique du Rwanda \& ORC Macro, 2005).

We focus on recent morbidity experiences of children under five years, specifically diarrhoea, cough, fever and Acute Respiratory Infection (ARI) symptoms as recorded in the 2005 RDHS. The predictor variables at the individual and household levels were selected based on the child survival and growth framework which classifies different proximate determinants associated with malnutrition and infections (Hatt \& Walters, 2006; Sreeramareddy et al. 2006; Erhardt et al., 2006; Filmer, 2005; Boadi \& Kuitunen, 2005; The Cebu Study Team, 1991; Mosley \& Chen, 1984). Socioeconomic and environmental factors mediate the synergic interactions between malnutrition and infections through a set of proximate determinants. This study addresses the direct and indirect pathways through which OVCs get exposed to morbidity risks taking into account the interactive effect of a range of household and individual (proximate) factors.

\section{Data and Methods}

Data on 3,747 children aged below 5 years extracted from the 2005 RDHS were considered for the present analysis. The survey collected detailed household data and other demographic and health information from women of reproductive ages. Data on child health were recorded for births that occurred during the five years preceding the survey (Institut National de la Statistique du Rwanda \& ORC Macro, 2005). Children who were classified as OVCs constituted $9.7 \%$ of the sample.

The main response variables of interest are diarrhoea, fever, cough and Acute Respiratory Infection (ARI) symptoms reported for the last two weeks preceding the survey. The RDHS asked if the child had any difficulties in breathing, specifically 
short, fast and unusual breaths. Children showing ARI symptoms were those who had been ill with a cough accompanied by short and rapid breathing. The response variables were dichotomous with children who experienced an illness coded "1" and "0" otherwise. The recall errors are assumed to be minimal since the events in question relate to a short period before the survey.

We used Graphical Chain Modelling (GCM) for the analysis. GCM is ideal for identifying direct and indirect determinants using regression models (Cox and Wermuth, 1996). This technique enables one to present the structure of associations in graphical form and enhances our understanding of the direct and indirect pathways of associations which are often difficult to capture in conventional regression modelling. The reader is referred to Wermuth (2005) and Lauritzen (1996) for a more detailed discussion on GCM. The explanatory variables were grouped into three blocks: (i) individual and household demographic and socio-economic factors; (ii) intermediate (proximate) factors and (iii) primary exposure variable (Figure 1). Prenatal and delivery care were selected as proxies to reflect access to healthcare (Whitehead et al., 1997). Source of drinking water and access to toilet facilities are considered proxies to ascertain the influence of health-related environment. Nutritional measures such as stunting and wasting considered important were not included in the analysis because anthropometric data for about $56 \%$ of children were recorded missing in the individual data file for various reasons, for example the child died or was away or living elsewhere at the time of survey. The statistical software used for the analysis was GraphFitI (Blauth \& Pigeot, 2000).

[---Figure 1 about here---] 


\section{Results}

Descriptive statistics

Table 1 shows the prevalence of diarrhoea, fever, cough and ARI symptoms among OVCs and non-OVCs. The distributions show that the prevalence of all four illnesses is higher among OVCs than non-OVCs. Chi-squared test revealed a significant difference in the prevalence of diarrhoea, fever and ARI symptoms between OVCs and non-OVCs at the $5 \%$ level but not for cough.

[--- Table 1 about here---]

\section{Associations among the outcome variables}

Figure 2 show that there exist direct associations among diarrhoea, fever and ARI symptoms but not between ARI symptoms and cough. The associations between diarrhoea, fever and cough imply that children who experienced diarrhoea are also more likely to experience fever and ARI symptoms and vice versa. The estimates presented in Table 2 show a positive association between cough, fever and diarrhoea, implying that a child who had diarrhoea is more likely to have a cough and or experience feverish conditions. About $54 \%$ of children who had diarrhoea also had fever, while $60 \%$ of those who had diarrhoea also had a cough. There is also a positive association between ARI symptoms, fever and diarrhoea which suggests that children who experience ARI symptoms are more likely to suffer from diarrhoea and fever. About $71 \%$ of all children who experienced ARI symptoms also had a fever. The associations are significant at the $1 \%$ level and remained significant even after adjusting for other relevant explanatory variables (Table 2). 


\section{Direct determinants of diarrhoea, fever, ARI symptoms and cough}

Figure 2 shows the direct determinants of diarrhoea, fever, ARI symptoms and cough. The green, pink, yellow and blue arrows show the direct associations of the pure explanatories, the intermediate factors and the primary exposure variable with diarrhoea, fever, ARI symptoms and cough, respectively. The figure shows that OVC status has a direct association with diarrhoea, fever and ARI symptoms but not with cough. The associations persist after accounting for demographic and socio-economic factors and are significant at the 5\% level. OVCs have increased odds of experiencing diarrhoea (48\%), fever (30\%) and ARI symptoms (39\%) compared to non-OVCs (Table 2).

The chain graph shows that, after accounting for OVC status, the intermediate factors directly associated with diarrhoea are breastfeeding, source of drinking water and prenatal care. Children who were not breastfed, those whose mothers received skilled prenatal care and those who live in households with access to safe drinking water are significantly less likely to have diarrhoea (Table 2). The pure explanatories directly associated with diarrhoea are age and sex of the child, the household structure and educational status of the mother/carer. Younger children have significantly higher odds of having diarrhoea compared to those aged 48-59 months (Table 2). The results also show that male children have increased odds (33\%) of having diarrhoea compared to female children. Children who lived in households with fewer adults have increased odds of having diarrhoea compared to children who live in households with four or more adults. Also, if a child's mother/carer has no formal education, his/her odds of having diarrhoea increases by $37 \%$ compared to a child whose mother/carer has secondary or higher education.

The chain graph shows that the only intermediate factor that has a direct association with fever is prenatal care (Figure 2). As expected, a child whose mother 
received skilled prenatal care has reduced (20\%) odds of having fever compared to a child whose mother received unskilled or no care. The pure explanatories that have direct association with fever are age of the child, household structure and natural region. The odds ratio shows that younger children are more $(27 \%)$ susceptible to fever (Table 2). Children who lived with three or less adults, those residing in the lake and marshy Southern and Eastern regions are also more susceptible to fever compared to those who live with four or more adults and those who reside in the City of Kigali.

The intermediate factors directly associated with children showing ARI symptoms are breastfeeding and prenatal care received by the mother (Figure 3). Currently breastfed children and those whose mothers received unskilled prenatal care have higher odds (45\% and $22 \%$ respectively) of showing symptoms of ARI compared to non breastfed children and those whose mothers received skilled prenatal care (Table 2). After adjusting for OVC status and the intermediate factors, the pure explanatories directly associated with ARI symptoms are the age of the child, birth interval and household structure. Younger children, those with lower preceding birth interval and those living with fewer adults in the household have higher odds of showing ARI symptoms.

Cough unlike diarrhoea, fever and ARI symptoms does not have a direct association with OVC status, even after adjusting for other significant factors. The only intermediate factor directly associated with cough is mothers' prenatal care status (Figure 2). Children whose parents received skilled prenatal care have reduced odds of having a cough (Table 2). The pure explanatories directly associated with cough, after adjusting for the other morbidities and prenatal care, are the age of the child, the number of household members, the region and place of residence. Also, the odds of having a cough are higher among younger children, children in households with 7 or 
more members and those residing in urban areas and the Southern region and City of Kigali.

[---Table 2 and Figure 2 about here---]

\section{Indirect determinants operating through OVC status}

The red arrows in Figure 3 show the intermediate factors and pure explanatories which operate through OVC status to influence childhood morbidity (diarrhoea, fever and ARI symptoms). The chain graph shows that vaccination, type of toilet facility and prenatal care operate through OVC status to influence childhood morbidity. Note that prenatal care operates directly and also indirectly to influence childhood morbidity. However type of toilet facility and vaccination only operate indirectly through OVC status. This suggests that the poor health outcomes of OVCs are also attributable to their vaccination status, environmental hygiene and access to healthcare (Table 3).

The pure explanatories that operate through OVC status to influence health outcomes of children are the age and sex of the household head, educational status of the mother/carer, natural region and place of residence (Figure 3). OVCs are more likely to be found in households headed by elderly persons (40+ years) and females, where the mother/carer has inadequate education and are more likely to be in urban areas and the south and eastern regions of the country (Table 3). This is an indication that the household structure of OVCs, their mother's/carers educational status and place of residence also contribute to their poor health outcomes. 


\section{Indirect determinants operating through intermediate factors and OVC status}

Figure 3 show the pure explanatories that influence childhood morbidity through the intermediate factors (vaccination, prenatal care and toilet facility) and OVC status. The pure explanatories that operate through the intermediate factors and through OVC status to influence child morbidity are age of the child, age and sex of the household head, birth order, educational status of the mother/carer, number of household members, natural region and place of residence.

From Figure 3 (Box 1) it can be noted that vaccination status acts with prenatal care and type of toilet facility to influence childhood morbidity, through OVC status. The implications are that OVCs health outcomes are not only worsened because they are more likely to have not received any vaccination (Table 3) but also because of health utilisation and environmental related problems that confront them. The pure explanatories which operate through vaccination and OVC status to influence child morbidity are age of the child, sex of the household head, the natural region and place of residence. Young and male children are less likely to have received any vaccination. Those in the South, West, North and Eastern regions and also from rural areas are also less likely to have received any vaccination compared to those in the City of Kigali and urban areas (Table 3).

Figure 3 (Box 1) shows that prenatal care operates collectively with sleeping under a bednet and place of delivery through OVC status to influence childhood morbidity. Mothers who receive skilled prenatal care are also more likely to have delivered in a health facility and their children are more likely to sleep under bed nets. This shows that OVCs health outcomes are poor not only because they have poor access to healthcare but also lack facilities that prevent illnesses such as bednets.

The pure explanatories which operate through prenatal care and OVC status are age of the child, age and sex of the household head, birth order, number of 
household members, educational status of the mother/carer and natural region. Mothers who received unskilled prenatal care are more likely to belong to households where the head is elderly (40+ years) and female, the mother/carer has no formal education or has only primary education and resides in the Southern region of the country (Table 3).

Type of toilet facility is another indicator which other intermediate factors (vaccination, sleeping under a bednet and place of delivery) operate with to influence childhood morbidity through OVC status (Figure 3, Box 1). The estimates in Table 3 and edges in Figure 3 show that health, environmental and preventive measures are collectively important determinants of childhood morbidity which can operate through OVC status. The pure explanatories which operate through type of toilet facility and OVC status are the number of household members, educational status of the mother/carer, natural region and place of residence.

[---Table 3 and Figure 3 about here---]

\section{Conclusions}

The results show a wide range of significant direct and indirect associations interacting both within and between the various sets of factors predicting poor child health outcomes among OVCs in Rwanda. The advantage of using GCM is that the factors that have no direct association with the outcome variables which are usually ignored were proven to be important, operating indirectly through other variables. The results show that OVCs have relatively a higher burden of ill-health when compared to non-OVCs. OVC status influences childhood morbidity directly and is a conduit through which other factors influence childhood morbidity. The intra-block associations show that all morbidity indicators are associated except coughing which is conditionally independent of ARI symptoms. This study also demonstrates evidence 
that some of the proximate and socio-economic factors operate both directly and indirectly through OVC status to influence childhood morbidity.

When considering the direct associations it is worth noting that healthcare utilisation, environmental hygiene and childcare factors such as prenatal care, source of drinking water and breastfeeding are important predictors of childhood morbidity. Nonetheless, vaccination status and type of toilet facility are not directly associated with childhood morbidity but they appear to have an indirect link to poor child health through OVC status. Vaccination status and type of toilet facility also act as a conduit through which a set of the socio-economic factors operate to influence poor child health through OVC status. This study presents evidence that poor healthcare utilisation, poor environmental conditions and lack of preventive measures contribute both directly and indirectly to poor health outcomes among OVCs. Socio-economic factors also aggravate the health outcomes of OVCs through a set of proximate factors and OVC status. Although previous studies had observed similar association between childhood morbidity and the proximate and socio-economic factors (Kandala et al. 2008; Kazembe et al., 2007; Kandala and Madise, 2004), this study contributed to a better understanding of the mediating effect of OVC status determining child health outcomes incorporating the interactive effect of proximate factors.

There are a few caveats in this study that are worth noting. Information on child morbidity was reported by mothers and not clinically validated. However, the reported morbidity experience is confined to the last two weeks preceding the survey. We believe that mothers are capable of understanding childhood illnesses and they are likely to provide accurate responses in the survey. On the other hand, DHS data are the only source that provides nationally representative population-level data on childhood morbidity. There is also lack of data on direct and indirect costs associated with healthcare, quality of health services delivery, and perceptions and beliefs related 
to healthcare seeking behaviour. Nonetheless, this study yielded policy relevant findings, particularly the role of direct and indirect factors which are methodologically difficult to establish otherwise.

From policy perspectives, an important finding of this study relates to the central role of OVC status in explaining poor child health outcomes. OVC status has a direct association with poor health outcomes; it also acts as a link through which many of the proximate and socio-economic factors operate to influence poor child health outcomes. The present study highlights the need to improve social and health care for OVCs, and the policy strategies that could be adopted to reduce childhood illnesses. More importantly, environmental hygiene, sanitation and preventive health measures should be given priority in programmes aimed at promoting better living conditions for OVCs. 


\section{References}

Andrews, G., Skinner, D., \& Zuma, K. (2006). Epidemiology of health and vulnerability among children orphaned and made vulnerable by HIV/AIDS in sub-Saharan Africa. AIDS care, 18, 269-276.

Bhargava, A., \& Bigombe, B. (2003). Public policies and the orphans of AIDS in Africa. British Medical Journal, 326, 1387-1389.

Blauth, A., \& Pigeot, I. (2000). GraphFitI - a computer program for graphical chain models. Collaborative Research Centre 386, Discussion Paper 224. http://epub.ub.uni-muenchen.de/1610/1/paper_224.pdf

Boadi, K.O., \& Kuitunen, M. (2005). Childhood diarrheal morbidity in the Accra Metropolitan Area, Ghana: socio-economic, environmental and behavioral risk determinants. Journal of Health \& Population in Developing Countries http://www.longwoods.com/product.php?productid=17646\&page $=60$

Cox, D.R., \& Wermuth, N. (1996). Multivariate Dependencies - Models, Analysis and Interpretation. Chapman \& Hall, London.

Ehrhardt, S., Burchard, G.D., Mantel, C., Cramer, J.P., Kaiser, S., \& Kubo, M., et al. (2006). Malaria, Anemia, and Malnutrition in African Children - Defining Intervention Priorities. The Journal of Infectious Diseases, 194, 108-114.

Filmer, D. (2005). Fever and its treatment among the more and less poor in subSaharan Africa. Health Policy and Planning, 20, 337-346.

Hatt, L.E., \& Waters, H.R. (2006). Determinants of child morbidity in Latin America: A pooled analysis of interactions between parental education and economic status. Social Science \& Medicine, 62, 375-386. 
Institut National de la Statistique du Rwanda (INSR) \& ORC Macro. (2006). Rwanda Demographic and Health Survey 2005. Calverton, Maryland, U.S.A.: INSR and ORC Macro.

Kandala, N.-B., Ji, C., Stallard, N., Stranges, S., \& Cappuccio, F.P. (2008). Morbidity from diarrhoea, cough and fever among young children in Nigeria. Annals of Tropical Medicine \& Parasitology, 102, 427-445.

Kandala, N.-B., \& Madise, N. (2004). The Spatial Epidemiology of Childhood Diseases in Malawi and Zambia. African Population Studies, 19, Sup. B, 199226.

Lauritzen, S. (1996). Graphical Models. Oxford Science Publications, Oxford.

Matshalaga, N.R., \& Powell, G. (2002). Mass orphanhood in the era of HIV/AIDS. British Medical Journal, 324, 185-186.

Mosley, W.H., \& Chen L.C. (1984). An analytic framework for the study of child survival in developing countries. Population and Development Review, 10, 2545.

Schenk, K., Ndhlovu, L., Tembo, S., Nsune, A., Nkhata, C., \& Walusiku, B., et al. (2008). Supporting orphans and vulnerable children affected by AIDS: using community-generated definitions to explore patterns of children's vulnerability in Zambia. AIDS Care, 20, 894 - 903.

Skinner, D., Tsheko, N., Mtero-Munyati, S., Segwabe, M., Chibatamoto, P., \& Mfecane, S., et al. (2006). Towards a Definition of Orphaned and Vulnerable Children. AIDS and Behavior, 10, 619-626.

Sreeramareddy, C.T., Shankar, R.P., Sreekumaran, B.V., Subba, S.H, Joshi, H.S., \& Ramachandran, U. (2006). Care seeking behaviour for childhood illness- a questionnaire survey in western Nepal. BMC International Health and Human Rights 6, 7. 
Stover, J., Bollinger, L., Walker, N., \& Monasch, R. (2006). Resource needs to support orphans and vulnerable children in sub-Saharan Africa. Health Policy and Planning, 22, 21-27.

The Cebu Study Team (1991). Underlying and proximate determinants of child health: The Cebu longitudinal health and nutritional study. American Journal of Epidemiology, 133, 185-200.

UNAIDS. (2008). Report on the global AIDS epidemic. Joint United Nations Programme on HIV/AIDS, UNAIDS

UNICEF. (2005). The state of the world's children: Childhood under threat. New York: UNICEF

UNICEF. (2006). Africa's orphaned and vulnerable generations: children affected by aids. United Nations

UNICEF. (2005). Guide to monitoring and evaluation of the national response for children orphaned and made vulnerable by HIV/AIDS. New York: UNICEF.

Wermuth, N. (2005). Graphical chain models. In: Everitt B, Howell DC (Eds.), Encyclopaedia of Behavorial Statistics II. Wiley, Chichester.

Whitehead, M., Evandrou, M., et al. (1997). As the health divide widens in Sweden and Britain, what's happening to access to care? British Medical Journal, 315, 1006-1009. 
Table 1. Prevalence (\%) of morbidity among OVCs and non-OVCs, Rwanda, 2005

\begin{tabular}{|c|c|c|c|c|}
\hline Indicators & All children & OVCs & Non-OVCs & $p$-value ${ }^{b}$ \\
\hline Diarrhoea & 14.2 & 19.1 & 13.7 & 0.007 \\
\hline Fever & 27.1 & 32.2 & 26.5 & 0.027 \\
\hline ARI symptoms ${ }^{a}$ & 17.3 & 21.0 & 16.9 & 0.036 \\
\hline Cough & 35.6 & 38.8 & 35.2 & 0.198 \\
\hline Number of children & 3741 & 339 & 3402 & \\
\hline
\end{tabular}

${ }^{a}$ children who had been sick with a cough accompanied by short, rapid breathing in the two weeks preceding the survey.

${ }^{b}$ for a chi-squared test. 
Table 2. Estimated odds ratios and confidence intervals of the direct determinants of the morbidity indicators

\begin{tabular}{|c|c|c|c|c|}
\hline \multirow[b]{2}{*}{ Explanatory variables } & \multicolumn{4}{|c|}{ OR $(95 \% \mathrm{CI})$} \\
\hline & Diarrhoea & Fever & ARI symptoms & Cough \\
\hline OVC status & & & & NS \\
\hline Non-OVC & 1.00 & 1.00 & 1.00 & \\
\hline OVC & $1.48(1.09,2.01)$ & $1.30(1.06,1.75)$ & $1.39(1.06,1.85)$ & \\
\hline Had diarrhoea & NA & & & \\
\hline No & & 1.00 & 1.00 & 1.00 \\
\hline Yes & & $2.44(1.94,3.09)$ & $1.71(1.35,2.16)$ & $1.76(1.39,2.21)$ \\
\hline Had fever & & NA & & \\
\hline No & 1.00 & & 1.00 & 1.00 \\
\hline Yes & $2.41(1.91,3.05)$ & & $9.73(7.99,11.86)$ & $13.63(11.37,16.34)$ \\
\hline Experienced ARI symptoms & & & NA & NS \\
\hline No & 1.00 & 1.00 & & \\
\hline Yes & $1.32(1.01,1.73)$ & $2.21(1.75,2.79)$ & & \\
\hline Had cough & & & NS & NA \\
\hline No & 1.00 & 1.00 & & \\
\hline Yes & $1.62(1.24,2.11)$ & $9.43(7.64,11.63)$ & & \\
\hline Breastfeeding & & NS & & NS \\
\hline Still breastfeeding & 1.00 & & 1.00 & \\
\hline Not breastfeeding & $0.49(0.41,0.59)$ & & $0.55(0.46,0.65)$ & \\
\hline Type of prenatal care & & & & \\
\hline Unskilled care & 1.00 & 1.00 & 1.00 & 1.00 \\
\hline Skilled care & $0.80(0.61,0.99)$ & $0.80(0.64,1.00)$ & $0.78(0.61,0.99)$ & $0.83(0.70,0.98)$ \\
\hline Quality of source drinking water & & NS & NS & NS \\
\hline Poor quality & 1.00 & & & \\
\hline Good quality & $0.78(0.63,0.97)$ & & & \\
\hline Age of child & & & & \\
\hline $0-23$ months & $2.91(1.90,4.47)$ & $1.27(1.00,1.73)$ & $1.51(1.06,2.15)$ & $1.91(1.51,2.41)$ \\
\hline $24-47$ months & $1.65(1.15,2.38)$ & $0.99(0.78,1.31)$ & $1.18(0.88,1.58)$ & $1.40(1.13,1.73)$ \\
\hline 48 - 59 months & 1.00 & 1.00 & 1.00 & 1.00 \\
\hline Sex of child & & NS & NS & NS \\
\hline Male & 1.00 & & & \\
\hline Female & $0.77(0.63,0.93)$ & & & \\
\hline Birth interval & NS & NS & & NS \\
\hline First birth & & & 1.00 & \\
\hline Less than 24 months & & & $0.85(0.63,1.13)$ & \\
\hline 24 or more months & & & $0.76(0.60,0.97)$ & \\
\hline Household structure & & & & NS \\
\hline 1 adult & $1.86(1.11,3.10)$ & $1.34(0.91,1.98)$ & $1.80(1.19,2.64)$ & \\
\hline 2 adults & $1.81(1.14,2.87)$ & $1.47(1.06,2.04)$ & $1.62(1.12,2.26)$ & \\
\hline 3 adults & $2.02(1.23,3.33)$ & $1.56(1.08,2.26)$ & $1.66(1.11,2.40)$ & \\
\hline $4+$ adults & 1.00 & 1.00 & 1.00 & \\
\hline Number of household members & NS & NS & NS & \\
\hline $1-3$ members & & & & $0.88(0.71,1.08)$ \\
\hline $4-6$ members & & & & $0.80(0.64,0.98)$ \\
\hline $7+$ members & & & & 1.00 \\
\hline Educational status of mother/carer & & NS & NS & NS \\
\hline No formal education & $1.37(1.09,2.06)$ & & & \\
\hline Primary & $1.26(0.86,1.85)$ & & & \\
\hline Secondary or higher & 1.00 & & & \\
\hline Natural Region & NS & & NS & \\
\hline City of Kigali & & 1.00 & & 1.00 \\
\hline South & & $1.45(1.05,2.00)$ & & $1.11(0.85,1.46)$ \\
\hline West & & $1.11(0.80,1.54)$ & & $0.77(0.58,0.99)$ \\
\hline North & & $1.12(0.79,1.59)$ & & $0.87(0.65,1.16)$ \\
\hline East & & $1.44(1.03,2.02)$ & & $0.86(0.64,1.16)$ \\
\hline Place of residence & NS & NS & NS & \\
\hline Urban & & & & 1.00 \\
\hline Rural & & & & $0.80(0.66,0.97)$ \\
\hline
\end{tabular}


Table 3 Estimated odds ratios and confidence intervals of the intermediate factors and pure explanatories

\begin{tabular}{|c|c|c|c|c|}
\hline \multirow[b]{2}{*}{ Explanatory variables } & \multicolumn{4}{|c|}{ OR $(95 \% \mathrm{CI})$} \\
\hline & $\begin{array}{l}\text { OVC vs. } \\
\text { non-OVC }\end{array}$ & $\begin{array}{l}\text { Skilled vs. } \\
\text { unskilled prenatal } \\
\text { care }\end{array}$ & $\begin{array}{l}\text { At least one } \\
\text { vaccination vs. no } \\
\text { vaccination }\end{array}$ & $\begin{array}{l}\text { Improved vs. } \\
\text { unimproved } \\
\text { toilet facility }\end{array}$ \\
\hline \multicolumn{5}{|l|}{ Intermediate factors } \\
\hline Vaccination & & & NA & \\
\hline No vaccination & 1.00 & & & 1.00 \\
\hline At least one vaccination & $0.71(0.56,0.90)$ & & & $1.28(1.14,1.40)$ \\
\hline Sleeps under a bed net & NS & & NS & \\
\hline No & & 1.00 & & 1.00 \\
\hline Yes & & $1.34(1.06,1.69)$ & & $2.12(1.79,2.52)$ \\
\hline Type of prenatal care & & NA & & \\
\hline Unskilled care & 1.00 & & 1.00 & \\
\hline Skilled care & $0.58(0.46,0.73)$ & & $1.80(0.67,1.96)$ & \\
\hline Place of delivery & NS & & & \\
\hline Home & & 1.00 & 1.00 & 1.00 \\
\hline Health facility & & $1.69(1.34,2.12)$ & $1.08(0.91,1.29)$ & $1.96(1.65,2.33)$ \\
\hline Toilet facility & & & & NA \\
\hline Unimproved & 1.00 & & 1.00 & \\
\hline Improved & $0.69(0.52,0.91)$ & & $1.77(1.65,1.92)$ & \\
\hline \multicolumn{5}{|l|}{ Pure explanatories } \\
\hline Age of child & NS & & & NS \\
\hline $0-23$ months & & $6.80(4.84,9.55)$ & $0.25(0.20,0.32)$ & \\
\hline $24-47$ months & & $2.19(1.73,2.78)$ & $0.64(0.53,0.78)$ & \\
\hline $48-59$ months & & 1.00 & 1.00 & \\
\hline Age of head of household & & & NS & NS \\
\hline $16-29$ years & $0.71(0.52,0.96)$ & $1.69(1.50,1.95)$ & & \\
\hline $30-39$ years & $0.61(0.47,0.80)$ & $1.67(0.53,1.84)$ & & \\
\hline $40+$ years & 1.00 & 1.00 & & \\
\hline \multicolumn{5}{|l|}{ Sex of household head } \\
\hline Male & 1.00 & 1.00 & 1.00 & 1.00 \\
\hline Female & $1.82(1.43,2.32)$ & $0.46(0.17,0.82)$ & $1.48(1.25,1.75)$ & $0.92(0.76,1.11)$ \\
\hline Birth order & NS & & NS & \\
\hline First & & $0.26(0.18,0.38)$ & & $1.10(0.84,1.43)$ \\
\hline Second and third & & $0.54(0.43,0.70)$ & & $1.10(0.91,1.33)$ \\
\hline Fourth or higher & & 1.00 & & 1.00 \\
\hline $4+$ adults & & & & \\
\hline Number of household members & NS & & NS & \\
\hline $1-3$ members & & $7.59(4.95,11.61)$ & & $0.46(0.33,0.64)$ \\
\hline $4-6$ members & & $2.03(1.60,2.58)$ & & $0.77(0.64,0.93)$ \\
\hline $7+$ members & & 1.00 & & 1.00 \\
\hline \multicolumn{5}{|l|}{ Educational status of mother/carer } \\
\hline No formal education & $2.24(1.31,3.80)$ & $0.68(0.47,0.97)$ & & $0.25(0.19,0.34)$ \\
\hline Primary & $2.09(1.27,3.44)$ & $0.72(0.53,0.99)$ & & $0.42(0.33,0.54)$ \\
\hline Secondary or higher & 1.00 & 1.00 & & 1.00 \\
\hline \multicolumn{5}{|l|}{ Natural Region } \\
\hline City of Kigali & 1.00 & 1.00 & 1.00 & 1.00 \\
\hline South & $1.84(1.16,2.92)$ & $0.70(0.50,0.96)$ & $0.60(0.45,0.80)$ & $1.03(0.76,1.39)$ \\
\hline West & $1.55(0.96,2.51)$ & $0.82(0.58,1.14)$ & $0.65(0.48,0.88)$ & $1.06(0.78,1.45)$ \\
\hline North & $1.14(0.67,1.91)$ & $0.93(0.66,1.33)$ & $0.72(0.53,0.98)$ & $0.48(0.34,0.67)$ \\
\hline East & $1.77(1.08,2.91)$ & $0.84(0.59,1.18)$ & $0.56(0.41,0.77)$ & $0.64(0.46,0.90)$ \\
\hline Place of residence & & NS & & \\
\hline Urban & 1.00 & & 1.00 & 1.00 \\
\hline Rural & $0.52(0.38,0.70)$ & & $0.71(0.57,0.88)$ & $0.78(0.62,0.97)$ \\
\hline
\end{tabular}


BLOCK 1: Socio-economic and demographic (pure explanatories)

Age of child Sex of child Birth order Birth interval Age of household head

Sex of household head Household structure Number of household members

Educational status of respondent Family religion Natural region Place of residence

\section{BLOCK 2: Intermediate factors}

Breastfeeding Vaccination Child sleeps under a bed net

Type of prenatal care Place of delivery Quality of source of drinking water

Type of toilet facility

BLOCK 3: OVC status

$\mathrm{OVC} /$ non-OVC

BLOCK 4: Morbidity indicators

Child morbidity (diarrhoea, fever, ARI symptoms and cough)

Figure 1. Framework for the determinants of child morbidity 


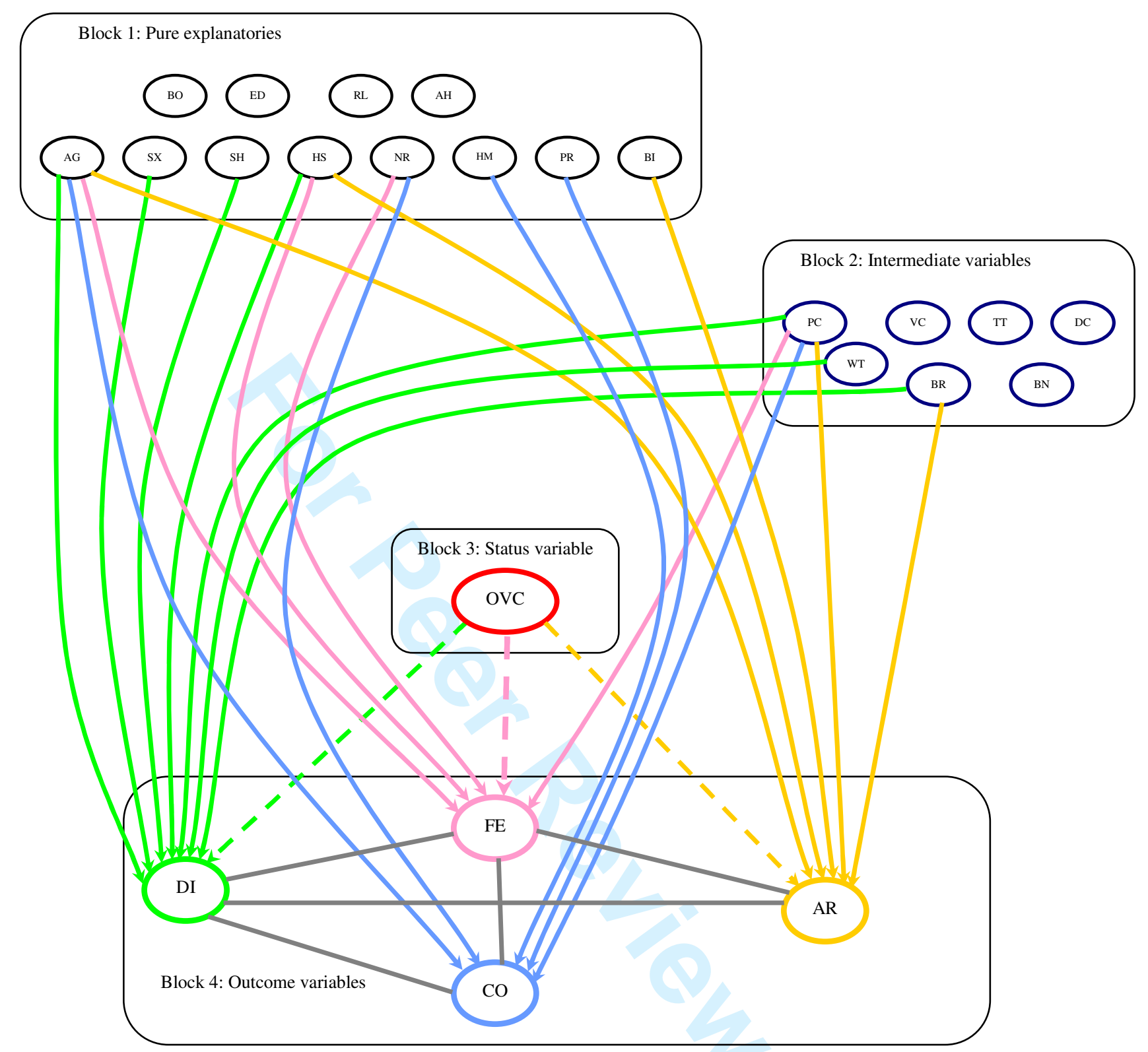

Block 4

DI - diarrhoea

$\mathrm{FE}$ - fever

$\mathrm{AR}$ - acute respiratory symptoms

$\mathrm{CO}$ - cough
Block 3

OVC - orphaned and vulnerable children
Block 2

$\mathrm{BR}$ - duration of breastfeeding

$\mathrm{VC}$ - child ever vaccinated

$\mathrm{BN}$ - child sleeps under a bed net

$\mathrm{PC}$ - prenatal care

DC - delivery care

WT - source of drinking water TT - Toilet facility

\section{Block 1}

AG - age of the child

SX - sex of the child

$\mathrm{BO}$ - birth order

$\mathrm{BI}$ - birth interval

$\mathrm{SZ}$ - size of the child at birth

$\mathrm{AH}$ - age of household head

$\mathrm{SH}$ - sex of household head

HS - household structure

HM - number of household members

ED - education of respondent

$\mathrm{RL}$ - religion

$\mathrm{NR}$ - natural region

$\mathrm{PR}$ - place of residence

Figure 2. Chain graph showing the direct determinants and the inter-block association for the morbidity indicators 


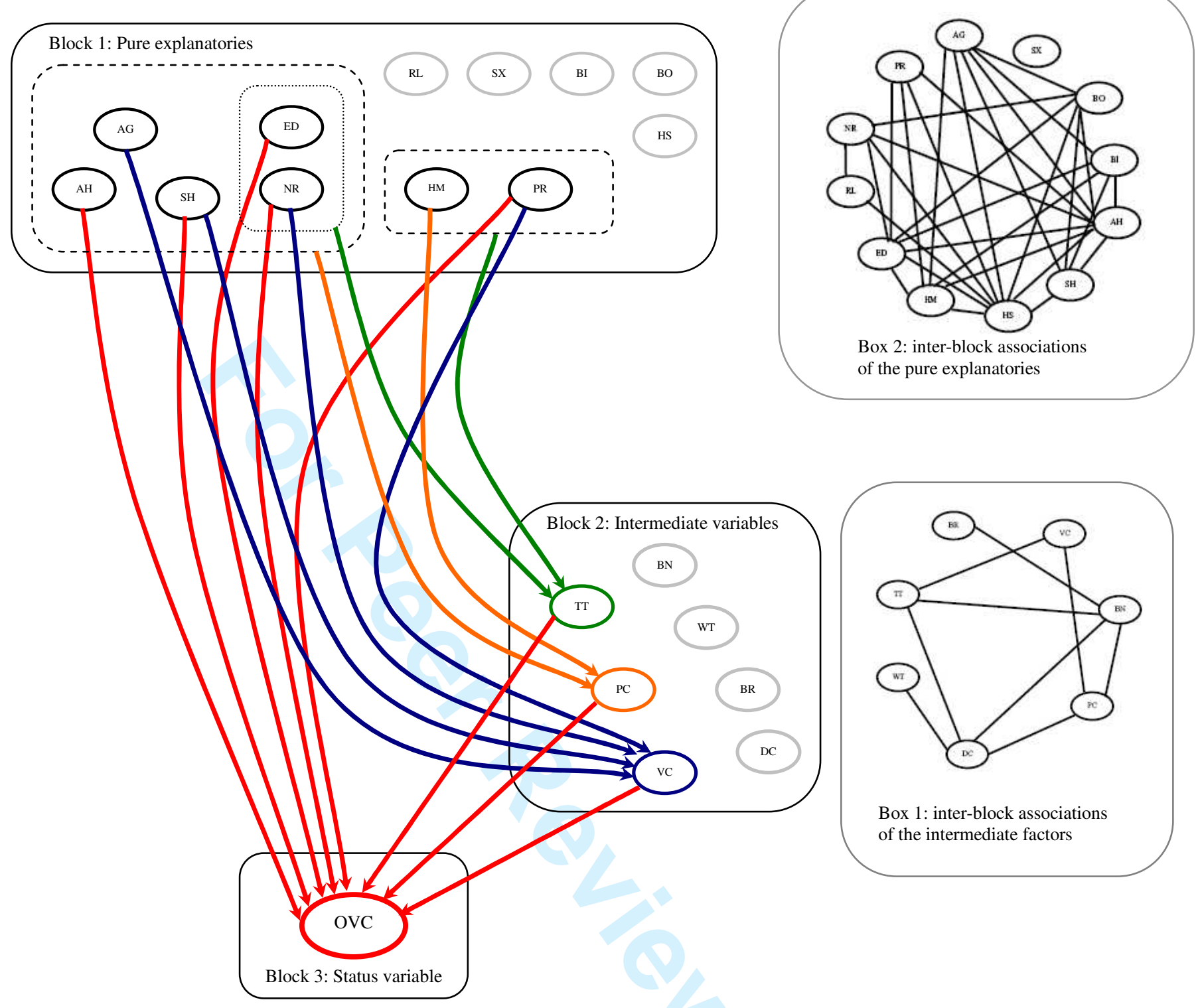

Block 3

OVC - orphaned and vulnerable children

\section{Block 2}

$\mathrm{BR}$ - duration of breastfeeding VC - child ever vaccinated

$\mathrm{BN}$ - child sleeps under a bed net $\mathrm{PC}$ - prenatal care

DC - delivery care

WT - source of drinking water

TT - Toilet facility

\author{
Block 1 \\ AG - age of the child \\ SX - sex of the child \\ BO - birth order \\ $\mathrm{BI}$ - birth interval \\ $\mathrm{SZ}$ - size of the child at birth \\ $\mathrm{AH}$ - age of household head \\ $\mathrm{SH}$ - sex of household head \\ HS - household structure \\ $\mathrm{HM}$ - number of household members \\ ED - education of respondent \\ $\mathrm{RL}$ - religion \\ $\mathrm{NR}$ - natural region \\ $\mathrm{PR}$ - place of residence
}

Figure 3. Chain graph showing the determinants that operate through the intermediate factors and OVC status 
Manuscript ID\# AC-2009-02-0085

Title: Orphanhood and vulnerability: a conduit to poor child health outcomes in Rwanda

\section{Revision notes}

We are very grateful to the referee for providing us with the comments and feedback on our manuscript. We have managed to address all the comments raised by the referee. The word count of the revised main text (without paper title and references) is 2988. The following notes explain how we reacted to each comment.

\section{General comments}

Comment 1: If this paper offers important new insights that might be useful in helping children, it does not report them in a way that is understandable, and it does not tell us how they might be used. "The aim of this paper is to disentangle the effect of underlying complex relationship between and within the proximate and socioeconomic factors that mediate poor health outcomes among children through their OVC status." This is OK, but you also need to say it in English, and then you need to say what it means. Why is it important?

Response 1: Thank you for this comment. We have made these clear in the revision. Please note that the revised text has been shortened following the instructions from the Editor. This study addresses the direct and indirect pathways through which OVCs get exposed to morbidity risks taking into account of the interactive effect of a range of household and individual (proximate) factors (explained on Page 2, last paragraph of the introduction). The relevance of the topic, the justifications and the rationale for using graphical chain techniques to model the mediating effect of OVC status and the complex association of factors in predicting child health outcomes have been addressed properly (also please see the conclusion section).

Comment 2: I confess that I have not fully understood the graphical chain analysis. The explanation is not all that clear. But more importantly, the paper provides me no reason for why I should spend more time and effort trying to understand it. OVC are more likely to be sick, and sick children are more likely to be sick. So what? How does your analysis help me address this? In the Introduction, you need to say why it's important to "disentangle the complex. ..." in the way you propose.

Response 2: The revision focuses more on the application and less on the methods. The methods section has been shortened, directing the reader to a few important references that provide a detailed explanation of graphical chain methods (Page 3, second paragraph). Also, please refer to Response 1.

Comment 3: "Policy-relevant findings" (Conclusion): What are they, specifically? "The central role of OVC status in explaining poor child health outcomes." OVC status itself doesn't explain anything. It's a category we put a child in. For programmatic purposes, wouldn't it be better to target kids in categories that directly explain poor health outcomes (e.g. kids whose families are poor, or kids who don't eat enough) rather than by OVC status? The last sentence (focus on young children, identifying especially those who lack health care, those living in female and elderly headed households and those from the poorest regions of the country) - are these 
things we haven't known before? The paper needs a discussion section. Among issues that cry out for discussion.

Response 3: The analysis clearly show that OVC status influences childhood morbidity directly and also indirectly as a conduit through which other factors influence childhood morbidity. The advantage of using GCM is that the factors that appear to have no direct association with the outcome variables which are usually ignored were proven to be important in explaining the indirect associations. The present study highlights the need to improve social and health care for OVCs, and the policy strategies that could be adopted to reduce childhood illnesses. More importantly, environmental hygiene, sanitation and preventive health measures should be given priority in programmes aimed at promoting better living conditions for OVCs. These points are stressed in the conclusion section. The conclusion section provides a brief discussion of the key policy implications. A separate discussion section is not included due to word restrictions.

\section{Specific comments}

1. The differences in prevalence of morbidity between OVC and non-OVC are not huge.

Given the sample of 3741 children, the differences are statistically significant for all morbidity outcomes at $p<0.05$, except for cough. . Furthermore, over $20 \%$ more OVCs than non-OVCs have these three morbidities. Please refer to Table 1 and the multivariate results reported in Table 2.

2. A footnote says that there's no info on HIV status of children; this would seem to be a major point in a discussion, since many of the health outcomes could conceivably be explained by HIV status.

Yes, we agree with this comment. To avoid confusion, the footnote has been removed from the paper.

3. What does it mean that OVC status is associated with some illnesses but not with cough? Does this result make sense?

The analyses show that children suffering from cough alone are not statistically different between OVCs and non-OVCs. However, ARI symptoms are significant which include illness with a cough accompanied by short and rapid breathing.

4. What does it mean that those were breastfed were MORE likely to be sick, and how does this fit with what is known about breastfeeding?

Breastfeeding status at the time of survey refers to current status for children underfive years. We could not include the duration of breastfeeding for censoring reasons as young children would have shorter duration when compared to their older counterparts. Regarding the results, currently breastfed children are less likely to suffer from diarrhoea (which is an important result) but they are likely to be suffering from ARI symptoms. It is likely that mothers are relatively more likely to breastfeed children who suffer from illness than healthy children and hence reported as such. 
5. What does it mean that households with more adults had less illness? Better child care and income (vs. cramped living conditions and less food)?

This might reflect the care given to OVCs in households with more adults (opportunity costs rather than economic costs).

\section{Other specific comments:}

Comment: Introduction - "These OVC live in deplorable conditions in households that are already poverty-stricken" - all of them?

Response: We removed this sentence in the revision since the survey data are inadequate to comment on this observation. Also, there is no information on the tenure of OVCs in the households interviewed in the RDHS.

Comment: The brief discussion of statistical methods should be in Methods, not the Introduction. Before we get to that, we should understand why this whole exercise is important.

Response: Thank you for this suggestion, we understand the point. The methods are discussed only in the 'data and methods' section.

Comment: The two-week window for child health problems is very short. You don't include malaria as an outcome?

Response: This is standard in all the Demographic and Health Surveys conducted across less developed countries. Most retrospective surveys rely on child morbidity data from the two weeks preceding the survey. This is the case even for specific follow-up studies, example the study by Goldman et al, 1998 on the use of calendars in measuring child morbidity (International Journal of Epidemiology (Vol. 27 Issue No. 3, pp. 505-512). We believe that mothers are capable of understanding childhood illnesses and they are likely to provide accurate responses in the survey. On the other hand, DHS data are the only source that provides nationally representative population-level data on childhood morbidity. The RDHS did not ask malaria outcomes among children.

Comment: "The conceptual framework proposed by Mosley and Chen. ..." This is deep in the Data and Methods section. It's needed for us to understand where we're going, should come much earlier.

Response: This is now discussed briefly in the introduction section (please see Page 2, last paragraph before the 'data and methods' section).

Comment: The exclusion of nutritional measures is too bad.

Response: Yes, we do agree with this point. Unfortunately, anthropometric data for about $56 \%$ of children were recorded missing in the individual data file for various reasons, for example the child died or was away or living elsewhere at the time of survey. Hence we could not include any nutritional measures.

Comment: In short, tell us why the study question is important, how your findings fit in with other studies (are they new? do they contradict? do they confirm?), and how they might be used to help kids. 
Response: Through graphical chain modelling, the study demonstrates new evidence that OVC status influences childhood morbidity directly and also a conduit through which other factors influence childhood morbidity. It concludes that the factors that have no direct association with the outcome variables which are usually ignored had indirect associations. These are elaborated in the revision. We gave careful attention to this comment while revising the manuscript. 